\title{
BIJ DE AUCANERS
}

III

DOOR

WILLEM F. VAN LIER.

Ik stel mij voor, dat de lezers van de West-Indische Gids het interessant zullen vinden om na het vorig artikel (De West-Indische Gids, 4e Jg. blz. 205) van de verdere afwikkeling van zaken betreffende het nieuwe tractaat te lezen. Ik bied hun daarom hierbij aan een verslag van de kroetoe (vergadering) waarin de stam, om dat nu maar zoo te noemen, het nieuwe verdrag heeft geratificeerd. Dit verslag geeft m.i. antwoord op de bewering, dat als het voortaan pais en vree met de Aucaners zal zijn, die niet door doch ondanks het tractaat zou bereikt zijn.

23 December I92I. Op heden kon de kroetoe, die aanvankelijk op 18 dezer bepaald was, doch door de Bilo-kapiteins verschoven, een aanvang nemen. De opkomst was zeer groot, nagenoeg alle kapiteins of hunne onder-kapiteins (Blaka djakti's) waren aanwezig en bovendien nog een groote schare ouderen ${ }^{1}$ ) en andere volwassen mannen die als belangstellenden waren opgekomen.

Bij de opening van de vergadering werd aan de Bilokapiteins verantwoording gevraagd voor het verzetten van den datum van 18 op heden. Kapitein Afaniaka van Manlobbi voerde het woord en bood namens alle Bilo-kapiteins aan de Opo-collega's excuses aan omdat deze gederangeerd werden. Wat aanleiding voor hen, de Bilomenschen, was den datum te verzetten, wilden zij nu liever

1) De ouderen vervullen bij de Aucaners de rol van volksvertegenwoordigers. 
verzwijgen en verzochten, dat er genoegen genomen zou worden met het aangeboden excuus en overgegaan tot de orde van den dag. Asékendé, de leider van de kroetoe, Amakti kon wegens ziekte de kroetoe niet in persoon leiden, doch woonde haar, in zijne woning, die vlak naast het kroetoe-huis staat, van het begin tot het einde toe bij had er bezwaar tegen dat de Bilo-kapiteins geen rekenschap van hun gedrag gaven en drong er op aan, dat Afaniaka zich nader zou verklaren. Deze bleef weigeren, doch zei geen bezwaar te hebben aan wien dit verlangde, particulier het een en ander mede te deelen. De Bilomenschen hebben bezwaar in de kroetoe over deze zaak te spreken; worden zij echter daartoe genoodzaakt, dan zullen zij uitkomen, doch de verantwoordelijkheid voor de wending die de debatten hoogstwaarschijnlijk zullen nemen blijve dan voor dengene die dat uitlokte, zeide Afaniaka.

Verschillende stemmen uit de kroetoe, waarschuwden Asékendé niet voort te gaan en de zaak werd daarbij gelaten ${ }^{1}$ ). Alsnu deelde Asékendé mede, dat deze bijeenkomst ten doel had aan den ganschen stam mededeelingen te doen van de reis van den Granman naar de stad en al wat daarmede in verband staat. Daar massa Van Lier de meest onpartijdige persoon is, die alles heeft medegemaakt en bovendien nog alles op papier heeft, werd hem verzocht het verslag uit te brengen.

Het woord is thans dus aan den heer Van Lier.

Ik hield, eer aan het verzoek van Asékendé te voldoen, eene toespraak tot de kroetoe, waarin ik wees op de goede bedoelingen van het Bestuur voor de Aucaners en stelde daartegenover hunne ondankbaarheid, welke zich uitte in gebrek aan vertrouwen in de Bakra's.

„Zoolang”, zeide ik ,gij niet uw vol vertrouwen aan de Bakra's schenkt en er van overtuigd wordt, dat bij al wat

1) Later vernam ik dat het verzetten van den datum door de Bilo-kapiteins als demonstratie tegen den Granman dienen moest. Als hun rekenschap gevraagd werd, dan zouden zij met hunne grieven tegen Amakti uitkomen. Kapitein Jenta van Powie had dit echter ontraden. Van mij had hij vernomen dat ik in deze kroetoe alle partijen met elkaar zou verzoenen en zag daarom liever dat er geen oude koeien uit de sloot gehaald werden. 
de Bakra's voor of weleens, in uw oog, tegen de Djoeka's doen, slechts één grondgedachte heerscht, nl. het waarachtig welzijn van uw stam, zoolang zal er geen sprake van vooruitgang bij $\mathrm{U}$ zijn. Ik heb twee jaar geleden met $\mathrm{U}$ den eed van trouw aan elkander gezworen. Ik deed dat met geheel mijn hart en heb woord gehouden. Gij daarentegen hebt dien eed geschonden; hoe was het anders mogelijk dat er zulke wantoestanden hier konden bestaan, terwijl ik in uw midden woon en bereid ben $\mathrm{u}$ in alles den weg te wijzen? Ik waarschuw u echter tegen u zelven; door mij niet geheel te vertrouwen zijt gij op een verkeerd pad dat u ten verderve zal leiden. Het doel van deze bijeenkomst is $\mathrm{u}$ allen bekend, het is het inluiden van een nieuw leven onder de Aucaners en daarom zal ik niet voortgaan met verwijten tot $\mathrm{u}$ te richten, maar u bekend maken met wat er zooal in de stad is voorgevallen gedurende de aanwezigheid van den Granman aldaar en u mededeelen de bevelen van den Gouverneur, waaraan gij voortaan te gehoorzamen hebt. Gij moogt mij straks zooveel vragen stellen als ge wilt, met betrekking tot de nieuw getroffen maatregelen. Ik zal al uwe vragen beantwoorden en $\mathrm{u}$ alles uitleggen wat gij wenscht te weten. De Gouverneur heeft mij bevolen dit te doen, want Zijne Excellentie wenscht dat alle Aucaners zullen weten waaraan zij zich zullen te houden hebben, omdat het Bestuur met onverbiddellijke strengheid de handen aan de nieuwe bepalingen zal houden".

Hierna verhaalde ik omstandig al wat had plaats gevonden van af Amakti's aankomst in de stad tot Gagoe's terugkeer van Albina zonder Aliamba. Met groote belangstelling luisterden allen. Veel indruk maakte het op hen dat aan Amakti dadelijk bij zijn aankomst te Paramaribo gelast werd de vlag van zijne boot neer te halen en dat het hem verboden was die uit te steken van het huis waarin hij logeeren zou; dat aan den Granman een verblijf in de Saramaccastraat werd aangewezen, terwijl Kanapé vlak bij de landskantoren mocht komen wonen, enz.

Ik legde toen uit waarmede deze „straffen” verband hielden. De vlag was aan den Granman gegeven om haar 
hoog te houden en te beschermen; in stede daarvan werd zij door hem misbruikt om zijn boot te tooien toen hij Aliamba zond om een afschuwelijk complot met de Boni's tegen de Bakra's te smeden.

Daar het 4 uur geworden was (de kroetoe was om 11 uur begonnen) stelde ik voor de voortzetting tot morgen te verdagen. Het gebruikelijke "go na see, kon pikie" (in comité gaan beraadslagen en komen antwoorden) vond toen plaats. Teruggekeerd in de kroetoe werd mij dank uitgebracht voor het gesprokene.

„Men had vele harde dingen aangehoord, doch niemand die mij iets kwalijk kon nemen, immers "na fa na krosi priti, na so a moe naai" (zooals het kleed gescheurd is, zoo moet het genaaid worden)". De kroetoe was mij vooral dankbaar, dat ik alles haarfijn vertelde, wat er zooal gebeurd was in de stad. „Geen Djoeka die in het openbaar al deze dingen zou rapporteeren; als altijd zouden wij nu weer hooren met hoeveel eer en onderscheiding de Granman is ontvangen en behandeld. Gelukkig dat er nu eindelijk iemand gevonden is, die geen oogenvrees heeft, enz."

Verder werd volmondig erkend, dat in al wat ik gesproken had, nog geen tikje ongelijk aan de zijde van de bakra's te vinden is.

's Avonds kwamen verschillende vrienden van Amakti mij vragen of het waar was, dat de Granman zelf aan de Bakra's verzocht had Kanapé met gezag te bekleeden. Dit hadden zij bij gerucht vernomen; de Granman zelf en Gagoe hadden hier verteld, dat de benoemingen van Kanapé en Gagoe geheel buiten Amakti om geschied waren. Ik antwoordde hierop, dat allen op den volgenden dag precies zouden hooren hoe dat in elkaar zit. Nog laat in den avond kwam een vertrouweling van Amakti mij verzoeken om den Granman niet aan de kaak te stellen „Uit schaamte had hij verzwegen, dat hij zelf de benoeming had uitgelokt". De verzoeker werd met een snauw weggezonden. „Ik was verontwaardigd over het feit dat men mij in gekonkel wilde betrekken".

24 December I92I. De kroetoe wordt voortgezet. Vele 
Missiedjan-negers (de tegenstanders van Kanapé bij uitnemendheid), w. o. Apientoe, Jententoe en Asoena, drie kopstukken der Missiedjanloo-negers, die gisteren er niet waren, komen heden uit. Het bericht had hen bereikt, dat ik vele „gewichtige dingen" gezegd had en dat er heden nog meer gezegd zouden worden. Ik ging voort met het verslag uitbrengen en schetste de verstoordheid van den Gouverneur over het wegblijven van Aliamba; voorts de angst van Amakti over wat met hem gebeuren zou en zijn biecht, dat hij de dupe thans is van zijn meineed, enz. De kroetoe luisterde met bijzondere aandacht. Ik ging voort en vertelde hoe Amakti zich toen tot het Bestuur wendde met de verklaring dat hij in het geheel geen gezag in de Tapanahony heeft; dat al zijne vrienden slechts schijnvrienden zijn, die het er op schijnen toegelegd te hebben hem ten val te brengen door hem in het kwaad te stijven en nooit anders dan slechten raad te geven; dat zijne oogen nu eindelijk zijn opengegaan en hij nu begrijpt dat Kanapé zijn eenige vriend is; dat hij dwaas gehandeld had Kanapé niet eerder zijn vertrouwen te schenken; dat hij thans echter een nieuw leven wenscht te beginnen en daarom den Gouverneur verzoekt Kanapé met gezag te bekleeden om hem te helpen den stam te besturen. Voorts verzoekt hij dat Gagoe aan Kanapé zou worden toegevoegd. De doodsche stilte waarin de kroetoe mij had aangehoord, werd nu verbroken. Uitroepen van verbazing, van afkeer tegen Amakti's huichelachtigheid, van medelijden met Kanapé, die zoolang de dupe van die huichelachtigheid geweest was, enz. werden luide geuit. $\mathrm{Na}$ verkregen stilte ging ik weer voort. Ik wees de kroetoe er op, dat Kanapé er niet bij was, toen de Granman het besluit nam bovenstaand verzoek tot het Bestuur te richten, doch Gagoe wel en die ging daarmede accoord. Jententoe: „Gagoe ben jij accoord gegaan met den Granman toen hij dat besluit nam?"

Gagoe: (stotterend) „Ja, anders zouden er soldaten en politie hier heen gezonden worden om ons te besturen".

Van Lier: Dat is een groote leugen Gagoe, je bent een huichelaar (joe dee konkroe) er was, toen de Granman het 
verzoek deed, nog geen sprake van soldaten en politie. Waarom lieg je uit oogenvrees?"

Jententoe: „Geef antwoord, Gagoe”.

Gagoe: (thans met forsche stem) "Ja ik heb den Granman gesteund bij zijn besluit, want ik heb de overtuiging dat Kanapé met rechtvaardigheid zal besturen, daarom heb ik mij beschikbaar gesteld om hem te helpen, en buitendien ik ben niemand rekenschap schuldig van mijne daden, ik heb in het belang van den stam gehandeld."

Jententoe zuchtte.

Van Lier: ik leg er nadruk op, dat de Granman den Gouverneur genaderd is met zijn verzoek, vóór het Bestuur zijn plannen om Kanapé met gezag te bekleeden aan de Djoeka's had bekend gemaakt. $\mathrm{Nu}$ wil ik jelui wel zeggen dat Kanapé in de stad ontboden werd om in Amakti's plaats, die onvoorwaardelijk zou worden afgezet, benoemd te worden. Toen evenwel Amakti zelf het verzoek tot den Gouverneur richtte om hem door Kanapé te doen bijstaan en daarbij volmondig zijn schuld erkende en nederig om vergiffenis vroeg, was dat naast de beden van den heer Smit en mij, reden voor den Gouverneur om terug te komen op Z.Ex.'s besluit en genade voor recht te laten gelden, onder de voorwaarde, die ik u straks zal voorlezen. Eerst wil ik over iets anders spreken. Ik heb sedert mijn terugkeer hier vernomen dat het lasterlijk praatje rondgebazuind wordt, dat Kanapé door gekuip heeft weten gedaan te krijgen van mij, dat ik zijne benoeming heb uitgelokt. Ik waarschuw jelui tegen het voortgaan daarmede. Je zult daarmede den Granman in nieuwe moeielijkheden brengen. Maar ook is het zonde iemand die zooveel voor den stam als wel voor Amakti persoonlijk in de stad deed als Kanapé, hier nog te belasteren". Ik somde toen op hoe Kanapé telkens en telkens trachtte bij den Gouvernements-Secretaris zoowel als bij andere hoofdambtenaren gunstige stemming voor den Granman te maken, en dat hij, in particuliere audientie bij den Gouverneur toegelaten, van die gelegenheid wist gebruik te maken $Z$. Ex. persoonlijk te verzoeken „al het gebeurde te willen vergeven en vergeten". 
Kanapé: „Het is nu genoeg over mijn persoon, meneer Van Lier".

Asoena: „Houd je er buiten Kanapé; meeneer Van Lier ga voort, laat ons alles vandaag hooren, verzwijg niets. Kanapé wees dankbaar aan dezen man, die een einde is komen maken aan het gekonkel tegen jou. Ik beken het nu, ook ik heb steeds behoord onder jouw tegenstanders, ik wil daarom nu weten hoe ik steeds misleid werd. Na jouw terugkeer, Kanapé, is mij gezegd geworden dat de Granman geheel buiten jouw benoeming stond. Die benoeming was een bevel van de Bakra's". En zich tot Apientoe wendende: „Apientoe, ontdek je nu dat bij den Granman het „,bloed kruipt waar het niet gaan kan” ten slotte gesproken heeft ? (libisoema no pooi prati broedoe $=$ de mensch kan bloed niet scheiden).

Apientoe: „Ik dank God dat de heer Van Lier gekomen is om een einde te maken aan het gekonkel van Djoeka's. Vóór den dood van Granman Oseisi wist iedereen dat Kanapé Granman worden zou; wel hij is het vandaag geworden. Amakti heeft zelf hem benoemd".

Jententoe: „Ik dank je, Apientoe voor je woorden, die mij uit het hart gegrepen zijn (joe go na mi bro foe hat$\mathrm{ti}=$ je bent in mijn hart geweest)".

Van Lier: „Granman, je zit wel in huis, maar je hoort toch alles wat hier gesproken wordt, is het niet? Is niet al wat ik hier gezegd heb precies zoo gebreurd?"

Amakti: (met forsche stem) „Ja, zoo is het gebeurd".

Kapitein Jenta van Powi: „Gods oordeelsdag is heden aangebroken (Gado kroetoedee kom tidee). Wie zijn het, die beweren dat Kanapé door invloed van den heer Van Lier benoemd werd? Laten zij dan aan Popo om inlichtingen vragen. Popo, hebben niet de Bakra's in de stad, toen jij met ons meeging om den Granman te installeeren, aan jou en Adihontoe gevraagd waarom jelui Kanapé het Granmanschap ontroofden ten behoeve van Amakti? Was de heer Van Lier er bij Popo toen jij en Adihontoe het lijk van Osessi geweld aandeden om Amakti als zijn opvolger te doen aanwijzen, zoo zelfs dat Adihontoe ge- 
struikeld is en jelui beiden lang uit met het lijk gevallen zijn?" „Popo, antwoord mij, lieg ik?”

Popo: „Neen”.

Jenta: „Popo is alles wat ik gezegd heb, waar?"

Popo: "Ja".

Kanapé riep mij ter zijde om mij te verzoeken een einde te maken aan hetgeen waarover thans gesproken werd, omdat de Granman haast bezweek onder de schande. „Hij, Amakti, is nu geheel losgelaten door zijn partij, laat ons hem dan de hoon besparen".

Terwijl ik met Kanapé ter zijde sprak ging kapitein Jenta voort de voormalige partijgenooten van Amakti, ongezouten de les te lezen. Ik maakte daaraan een einde door Jenta te verzoeken niet voort te gaan. „Alles is nu voorbij, kapitein, wij beginnen van heden af een nieuw leven, laat ons dan alles met den mantel der liefde bedekken".

Ik vertelde nu hoe de Gouverneur ten slotte besloot genade voor recht te doen gelden voor Amakti, doch dat er nog een bedenkelijk punt overbleef; Z.Ex. bleef nl. bij den eisch dat Aliamba goed of kwaadschiks zou komen, en waar zij in het begin aan Amakti had doen weten dat het voor Z.Ex. slechts kinderspel was Aliamba uit de Tapanahony te doen halen, wilde zij dit ook met de daad bewijzen.

Het was reeds laat op een avond toen ik bericht kreeg, dat de Gouverneur besloten had eene expeditie van twaalf soldaten onder een luitenant naar de Tapanahony te zenden, via de Sarakreek, om Aliamba af te halen. De soldaten zouden dan op het dorp van Aliamba verblijf houden tot deze was uitgeleverd (groote ontsteltenis in de vergadering). Op dienzelfden avond nog verzocht ik om gehoor bij den Gouverneur. Z.Ex. weigerde in het eerst mij te ontvangen. Zij was moe geworden van mij zoo vaak te moeten aanhooren met smeekbeden voor de Djoeka's. Toen ik bleef smeken om toegelaten te worden, stond de Gouverneur mij ten slotte een onderhoud toe. Ik verzocht dat $Z$. Ex. zou afzien van het plan soldaten naar de Tapanahony te zenden. „Geen sprake 
daarvan" antwoordde de Gouverneur.Toen wees ik Z. Ex. op de noodlottige gevolgen, die deze expeditie zou hebben. De vele jonge vrouwen in verwachting zouden als zij eensklaps soldaten van uit het bosch zagen verschijnen, in hare verwachtingen teleurgesteld worden en hoe velen zouden misschien niet aan de gevolgen daarvan sterven. Toen zag ik welk een goed hart onze Landvoogd heeft. Hij, die zoo streng is, wiens ja, ja en neen, neen is, gaf dadelijk toe. „Terwille van de jonge vrouwen in verwachting zal ik geen soldaten er heen zenden", zeide de Gouverneur „doch Aliamba zal gestraft worden” (veel beweging in de vergadering). Ik kon niet voortgaan met mijn rede. Apientoe ${ }^{1}$ ) riep uit: „Ik schors de kroetoe, broeders komt met mij in comité".

De vergaderzaal liep bijna leeg. $\mathrm{Na}$ terugkeer sprak Apientoe „Massa Van Lier, namens alls Djoeka's zeg ik jou dank. Alle Djoeka's danken jou op hun knieën voor wat je voor ons gedaan hebt. Menschen kunnen jou daarvoor niet loonen, je loon is dus bij God. Je hebt op gisteren gezegd dat je je eed met ons getrouw gebleven bent, met deze daad heb je de bewijzen daarvoor geleverd. Je hebt zoo vaak verklaard dat je Djoeka bent, wel vandaag verklaren de Djoeka's, dat je niet alleen Djoeka bent, maar je bent de eerste onder alle Djoeka's" (zoo iets van eere-burger in de Tapanahony, stel ik mij voor). „Dat je het eerst aan onze vrouwen, zusters en dochters in verwachting gedacht hebt, geeft jou aanspraak op levenslange dankbaarheid van den ganschen stam". En tot de kroetoe zich richtend: „Broeders, neemt dezen man in uw midden op zooals hij zich geeft, hij is geen leugenaar. Een leugenaar praat niet als hij."

$\mathrm{Na}$ een „stormloop” van allen, die mij (Djoeka-gebruik) wenschten te omhelzen, te hebben doorstaan, verzocht ik om de kroetoe, die heden weer vier volle uren geduurd had, te verdagen tot morgen.

25 December I92I. De dag wordt heden hoofdzakelijk besteed aan het voorlezen van het protocol en het uit-

1) Zie van Lier. Iets over de Boschnegers blz. 89 en 90. 
leggen punt voor punt daarvan. Vragen werden er slechts weinig gesteld. Op mijn aandringen dat er nog meer gevraagd moest worden, omdat het de wil van den Gouverneur was dat allen precies zullen weten en begrijpen wat er in dat stuk staat, werd geantwoord dat na de uitlegging, die ik van alles gegeven had, er geen ruimte voor vragen meer bestond.

Nadat ik klaar was met voorlezen en uitleggen, gingen weer nagenoeg alle aanwezigen in comité. Teruggekeerd, werd bij monde van dà Afaniaka in eene rede, die wel een uur duurde een overzicht gegeven van al wat was voorgevallen, van de wantoestanden, die successsievelijk in de Tapanahony ontstaan waren, van de gespannen verhouding tusschen den Granman en zijne kapiteins, van den toestand van regeeringgloosheid, die hier dreigde te ontstaan, enz. totdat de Bakra's eindelijk hebben ingegrepen. In al wat voorgelezen werd stond niets dat niet is in het belang van de Djoeka's en daarom werd alles met blijheid aanvaaid. Voorts werd mij verzocht hiervan bericht aan den Gouverneur te zenden. Ik dankte hiervoor en hield weer eene rede waarin ik vooral wees op het gevaar dat voor elk volk bestaat in het verdeeld zijn in partijen. Eendracht is de eerste voorwaarde voor elk volk om tot bloei en welvaart te geraken. Ik deed daarom een krachtig beroep op alle Aucaners om van heden af alle oude veeten te laten rusten, als dood en begraven te beschouwen. Broederliefde is het hoogste gebod van God aan den mensch. „Laten wij dan, broeders, ter wille van God en onze zaligheid dit gebod getrouw naleven".

Mijne woorden schenen indruk gemaakt te hebben; nadat in comité beraadslaagd was, dankte Afaniaka mij voor al wat ik gezegd had namens de kroetoe en werd aan Jenta (als oudste in jaren) opgedragen te mijnen behoeve een offer aan de goden en gran-jorka's te plengen.

$\mathrm{Na}$ weer talrijke omhelzingen doorstaan te hebben, verdaagde ik de kroetoe tot den volgenden dag.

26 December I92I. Van de goede stemming, die er onder de vele leiders van het volk, hier aanwezig, heerschte, 
wilde ik zooveel mogelijk partij trekken. Ik overlegde daarom met Kanapé mijn plan om meteen een einde te maken aan de afschuwelijke gebruiken als lijfstraf, het vele dagen boven aarde houden van lijken, enz., waarover de Gouverneur en Gouvernements-Secretaris hunne afkeuring te kennen hadden gegeven. Kanapé was dadelijk enthusiast over dit plan en verzocht mij om, nadat ik in de kroetoe daarover zou gesproken hebben, hem voor de verdere afwikkeling daarvan te willen laten zorgen.

Bij de voortzetting van de kroetoe op hedenmorgen deelde ik mede, dat er nog meer bevelen van den Gouverneur waren, die ik nu bekend zou maken; deze bevelen zijn op uitdrukkelijk verzoek van den GouvernementsSecretaris en mij niet in het stuk dat ik op gisteren heb voorgelezen aangehaald, omdat van alles wat schriftelijk is vastgelegd de Koningin inzage neemt, en de Gouvernements-Secretaris en ik zouden ons diep schamen als H.M. te weten kwam, dat een deel van Hare onderdanen nog zulke onteerende gebruiken er op na hielden.

De Gouverneur had aan dit verzoek toegegeven, nadat ik de verantwoordelijkheid op mij genomen had, dat $Z$. Ex's bevelen ook zonder op papier te staan stipt zullen nagekomen worden.

Die bevelen luiden:

$1^{\circ}$. Lijfstraf in welken vorm ook wordt van heden af afgeschaft.

$2^{\circ}$. Geen lijk mag langer dan drie dagen boven aarde gehouden worden.

$3^{\circ}$. Lijken van wisi-mans mogen niet meer weggeworpen, doch moeten voortaan begraven worden.

Kanapé nam nu het woord. In een krachtige rede wees hij er op dat men hem altijd hier verweten had, dat hij de Bakra's te veel aanhing; en hoe staat het nu? Alle Djoeka's eenparig verklaren thans overtuigd te zijn van de goede bedoelingen van de Bakra's. Hij zou geen verwijten doen, doch slechts zijn vreugde erover uiten dat de oogen hier thans zijn opengegaan.

Hij is nu met gezag bekleed, hij heeft nooit daarom gevraagd, doch eenmaal de benoeming aangenomen wilde 
hij thans aan allen zeggen, dat hij zijne belofte aan de Bakra's gedaan om voor de naleving van de bevelen van den Gouverneur zorg te dragen, gestand zou doen, ook al zou dat hem zijn hoofd kosten.

„De bevelen van den Gouverneur zooeven door den heer Van Lier medegedeeld, werden in de stad met ons besproken en wij hebben instemming daarmede betuigd".

Amakti interrompeert: "Ja, ik heb beloofd dat aan al deze dingen een einde zal komen".

Kapané vervolgt: „Kapitein Aloei en Adam, is al wat ik hier verklaar, juist?"

Aloei en Adam: „Geheel juist”.

Kapitein Adam deelde verder mede dat hij het bovenstaande, behalve in een desbetreffende kroetoe ook nog persoonlijk aan den Gouvernements-Secretaris had beloofd en nam de gelegenheid te baat zijn persoonsindruk van ZHEdGestr. te vertellen: ,een knap uitziende jongeman, ijselijk streng en toch zoo vriendelijk en welwillend, een man aan wien niemand iets dat hij vraagt zou kunnen weigeren".

Kapané vervolgde zijne rede en vertelde dat hij in eene particuliere audientie bij den Gouverneur toegelaten, $Z$ Ex. plechtig beloofd had dat hij streng de hand aan alles, en in het bijzonder aan deze maatregelen zou houden.

Met $Z$ ijne Excellentie was verbleven hoe voortaan gehandeld zou worden. Hij lichtte de vergadering daaromtrent in.

$\mathrm{Na}$ de gebruikelijke beraadslaging in comité, werd bij monde van kapitein Popo verklaard, dat deze dag een dag van zegening Gods is, nu een einde gekomen is aan zooveel waaronder de Djoeka's zuchtten, doch waarin nooit verandering zou komen zonder hulp van de Bakra's, aangezien het hier gaat om "gebruiken onzer voorvaderen."

Kapitein Jenta van Powie verklaarde dat hij met veel genoegen de afwikkeling van deze kroetoe had bijgewoond. Hij dankt God, dat hij vóór zijn dood nog zooveel goede veranderingen in het leven van de Aucaners heeft zien komen. Hij deed een krachtig beroep op de aanwe- 
zigen om het onderwijs zooveel mogelijk te steunen. „Het toekomstig geslacht zal U daar levenslang dankbaar voor zijn" besloot Jenta zijne toespraak.

Thans wenschte de kroetoe te weten hoeveel scholen er gesticht worden en waar die zullen geplaatst worden. Ik antwoordde dat er voorloopig ééne school kwam, op mijn standplaats.

„Maar dan worden de Opo-kinderen van het onderwijs uitgesloten", riepen verschillende stemmen.

Ik legde uit dat de Opo-kinderen en die van Granbilo (Manlobbi en omstreken) bij mij zouden komen inwonen.

Gevraagd werd of ik wel onderdak en voedsel voor al die kinderen zou hebben ,want, de een zal niet aan de anderen mogen voorgetrokken worden".

Ik zette uiteen dat met deze eerste school slechts een proef genomen wordt; slaagt die, d. w. z. komen de leerlingen getrouw ter school en toonen de ouders daarop prijs te stellen, dan zullen er meer scholen in andere centra opgericht worden. $\mathrm{Na}$ een korte pauze verzocht ik weer om stilte. Ik had nog een boodschap van den Gouverneur en van den Districts-Commissaris over te brengen. Vóór daartoe over te gaan, las ik voor de rede van ZEx., tot afscheid aan Amakti en de zijnen, op 20 September. Deze rede maakte veel indruk op de kroetoe en een juichtoon ging aan het einde daarvan op. De boodschap van den Gouverneur, die ik nu moest overbrengen, luidde: „Het had Z Ex. veel leed gedaan, dat Zij dadelijk bij haar aankomst in de kolonie streng tegen de Aucaners moest optreden. Zij was daartoe door de Aucaners zelf genoodzaakt geworden. De Gouverneur wenschte echter van ganscher harte dat het leven tusschen de Aucaners en de Bakra's voortaan gaan zou, zooals nu is verbleven en dat in vervulling zou komen de wensch van $Z$ Ex. aan het slot van haar rede nl. dat als de Granman weer in de stad ontboden werd, het dan niet zijn zou om berispt te worden, doch om aan den Gouverneur de blijde tijding te brengen, dat de Djoeka's in tevredenheid leven en in elk opzicht vooruit gaan." De juichtonen van de kroetoe duurden hierop lang. 
De Districts-Commissaris had mij opgedragen zijne groeten over te brengen. ZEdGestrenge is geen vreemdeling voor de Djoeka's, integendeel, weinigen die hem niet kennen uit den tijd toen hij als secretaris op Albina was. De Djoeka's weten dan ook reeds van vroeger dat hij hun zeer genegen is en altijd hunne belangen heeft behartigd.

$\mathrm{Nu}$ Commissaris geworden, zal ZEdGestrenge op dezelfde wijze als voorheen die belangen blijven bevorderen. Hij vraagt daartegenover het volle vertrouwen van de Djoeka's want zonder dat vertrouwen zal het hem niet mogelijk zijn iets blijvends in hun belang te doen.

"Ten slotte nog dit, broeders. Toen de Granman en de kapiteins uit de stad vertrokken, hadden zij geen tijd meer met het Bestuur te spieken over de nooden en klachten der Djoeka's. Ik heb toen beloofd, dat ik na hun vertrek het een en ander aan het Bestuur zou blootleggen en om hulp verzoeken. Dat heb ik ook gedaan.

Ik ben echter tot u teruggekeerd zonder vracht (Djoeka-beeldspraak), maar geheel leeg is mijn boot ook niet. Zonder vracht, want ik kan $U$ niet zeggen, dat aan alles waarover gij klaagt, reeds vandaag of morgen een einde zal komen. Maar geheel leeg is mijne boot ook niet, want de Gouverneur doet U weten, dat ZEx. aan alles haar aandacht zal schenken.

De nieuwe Commissaris doet U weten dat hij het zich tot taak zal stellen te zorgen, dat de Djoeka's niet - door wien dan ook - worden uitgebuit. Om dat te kunnen doen is echter voor hem noodig, dat de vrachtvaarders zich geregeld bij hem aanmelden voor het invullen van de livretten bij het opvaren zoowel als bij het afzakken. ZEdGestrenge zal daarom zeer streng de hand aan het livretten-stelsel ${ }^{1}$ ) houden.

Popo: „Meneer Van Lier, u heeft gezegd, dat u geen vracht voor ons gebracht hebt, broeder, uw boot is tot zinkens toe geladen. Zend onzen dank aan den Gouverneur, aan den Gouvernements-Secretaris en den Commissaris.

1) Zie De West-Indische Gids, 4de jg. (Mei 1922), blz. 51. 
Van Lier: „En hiermede ouderen, heb ik de taak, die ik op mij nam, voleindigd. Ik heb u volledig verslag van den stand van zaken gegeven. Gij hebt mij gedankt voor al wat ik voor u deed, dien dank neem ik aan, doch beschouw dien als een vorm van beleefdheid. Op werkelijken dank heb ik geen aanspraak, immers, en ik verklaar dat nu weer; ik beschouw mijzelf geheel als Djoeka, wat ik deed, deed ik dus voor mijzelf en niemand heeft aanspraak op dank voor hetgeen hij voor zichzelf doet. Stel u voor dat gij bij het loopen in het bosch een grooten splinter in uw voetzool kreeg, dien gij met een scheermes moest uitsnijden om geen infectie te krijgen en misschien uw been verliezen. Zoudt gij uzelven dank zeggen voor het behoud van uw been? Neen toch. Wel dan, een einde maken aan de vele wantoestanden - in hoofdzaak het gekonkel, waarin mijn stam leefde, was mijn plicht. Het was het uitsnijden van een gevaarlijken splinter. Dat de operatie pijn, aan sommigen zelfs veel pijn heeft gedaan, was niet te vermijden. Het been moest behouden blijven. Ik zal steeds blijven voortgaan op den weg, dien ik tot nu toe gevolgd heb. Dat ik hier reeds veel goeds gedaan heb, zal ik niet beweren; groot zou mijn dwaasheid zijn als ik dat deed. Wat ik echter wel beweer, is dat ik steeds mijn plicht tegenover het Bestuur en tegenover den stam gedaan heb en zal blijven doen.

Mi koti” (,Ik heb gezegd”).

Volgens Djoeka-gebruik verwijderde ik mij om aan de kroetoe gelegenheid te geven over alles wat behandeld was, nog eens van gedachten te wisselen. Na ruim een uur werd ik teruggeroepen. Bij monde van Asedé (Missiedjanloo) verklaarde de kroetoe dat al de wetten en bevelen van den Gouverneur zonder eenig voorbehoud zijn aanvaard en dat alles stiptelijk zal worden nageleefd. De Gouverneur gelieve het te beschouwen alsof niet de Granman met eenige Hoofden met $\mathrm{ZEx}$. de overeenkomst gesloten hebben, doch dat geheel de stam bij de onderhandelingen tegenwoordig was. Aan den Granman en Kanapé werd opgedragen een brief aan den Gouverneur te schrijven om het bovenstaande aan $\mathrm{ZEx}$. te berichten. Ik 
dankte hiervoor, doch wenschte nog één vraag te stellen: „Hebt gij hetgeen uwe Hoofden bij de Bakra's aanvaardden, bekrachtigd uit nooddwang of is dat met geheel uw hart geschied? (Na foe die tee man moro joe a doro joe mama-hedé gi joe foe tjari, joe sa tjari? ifi nanga krin brô foe hatti? Is het omdat wanneer een man u overmeestert en hij snijdt uw moeders hoofd af en geeft $\mathrm{u}$ dat te dragen, gij het dan dragen zult, of is het met een schoon hart?)

Spontaan klonk het „geen sprake daarvan (kwetikweti) het is met geheel ons hart (nanga krin brô-foehatti)".

,Wel broeders, dan dank ik u op mijn beurt met geheel mijn hart. Moge Nana (het Opperwezen) ons allen bijstaan".

's Avonds hield ik nog een babbeltje met Kanapé over al wat er gedurende de vier dagen zooal besproken was. Hij verklaarde mij dat hij nooit zooveel succes had durven verwachten.

Op mijn vraag of hij al wat door de kroetoe beloofd was, als oprecht gemeend beschouwde, antwoordde hij volmondig ,ja”. 